Research Article

\title{
Experimental Study on the Shear Behavior of Bolted Concrete Blocks with Oblique Shear Test
}

\author{
Bo Meng $\mathbb{D}^{\mathbb{D}}$, Hongwen Jing, Shengqi Yang, Yingchao Wang $\mathbb{D}$, and Biao Li \\ State Key Laboratory for Geomechanics and Deep Underground Engineering, School of Mechanics and Civil Engineering, \\ China University of Mining and Technology, Xuzhou 221116, China
}

Correspondence should be addressed to Bo Meng; 15365857985@163.com

Received 24 December 2017; Accepted 18 March 2018; Published 8 May 2018

Academic Editor: Rihong Cao

Copyright (c) 2018 Bo Meng et al. This is an open access article distributed under the Creative Commons Attribution License, which permits unrestricted use, distribution, and reproduction in any medium, provided the original work is properly cited.

The shear behavior of concrete blocks reinforced by fully grouted bolts with different diameters was studied in this paper. More than 90 intact cubic samples $(100 \mathrm{~mm} \times 100 \mathrm{~mm} \times 100 \mathrm{~mm})$ with bolts ranging from $2 \mathrm{~mm}$ to $5 \mathrm{~mm}$ in diameter were tested at a constant stain rate of $0.5 \mathrm{~mm} / \mathrm{min}$. An oblique shear apparatus, which could simultaneously apply shear and normal force on tested samples at three slope angles $\left(53^{\circ}, 58^{\circ}\right.$, and $\left.63^{\circ}\right)$ of a predetermined shear plane, was employed. The results indicate that the bolt has no evident influence on the shear behavior of intact concrete blocks at the prepeak shear strength stage. The bolt could significantly reduce the shear strength drop in the peak shear strength of the concrete block and contribute to reserving the residual shear strength of concrete blocks, especially at steep slope angles of the shear failure plane. The shear resistance provided by the bolt to the concrete block at the residual shear slip stage has a positive relationship with the diameter. The bolt with a larger diameter inflected in the vicinity of the shear failure plane of concrete block at the postpeak shear strength stage; additional normal force and direct shear resistance could still be persistently provided. Two empirical equations of the apparent cohesion and apparent internal angle of the bolted concrete block were obtained by linear regression considering $r_{\mathrm{b}}$, which is the ratio of the cross-sectional area of the bolt to that of the bolted concrete block.

\section{Introduction}

Rock bolts have been widely used in civil engineering, mining, and slope stability control engineering for many years. Many valuable studies on the reinforcing mechanisms of rock bolts have been carried out, primarily on three aspects including (1) strengthening the effect of the bolt on a single joint [1-6], (2) the working mode of bolts under axial or horizontal loads [7-11], and (3) the apparent shear or compression mechanical behavior of bolted rocks [12-14].

Initially, these studies mainly concentrated on the influence of bolting or joint parameters (inclination, pretensioning load, diameter of bolt, and rock type) on the mechanical behavior of joints, such as stiffness, shear resistance, and bolt failure. Bjurström [1] conducted research on the direct shear test on fully bonded rock bolts embedded in blocks of granite. It indicated that the pre-tension load, friction of joints, and inclination of bolts could stiffen the shear surface. Azuar [15] studied the strengthening mechanics of resin-grouted bolts embedded in concrete by laboratory tests. It was concluded that the maximum contribution of a rock bolt to the shear resistance of a joint depended on the inclination of the bolt. Hibino and Motojima [16] carried out shear tests with ungrouted $2 \mathrm{~mm}$ diameter bolts in concrete blocks and found that the pretension load of the bolt reduced the shear displacement but did not influence the shear resistance of bolted concrete blocks. Dight [17] studied the shear resistance of bolted joints using various materials, including gypsum, basalt, and steel, and revealed that the bolts were loaded by a combination of shear and tension stresses. Egger and Fernandez [18] studied the influence of the inclination of bolts to the shear resistance and stiffness of bolted joints. The results indicated that the optimum angle of bolt inclination with respect to the joint was $30^{\circ}$ to $60^{\circ}$, and shear displacements at 
failure were minimal for bolt inclinations between $40^{\circ}$ and $50^{\circ}$. Egger and Zabuski [19] carried out shear tests on bolted concrete blocks without an external normal force. It was found that bolts worked as an additional resistance against shear failure along joints and made entire rock mass become stronger and deform less. The stiffening effect of inclined bolts on joints has been widely approved. Pellet and Egger [20] noted that bolts installed perpendicular to a joint plane allowed the greatest displacement along the joint before failure. Indraratna et al. [5] studied the shear behavior of bolted and nonbolted joints containing infill material under constant normal stiffness conditions. The results show that bolting contributed to increasing the strength and stiffness of the joint composite, except at large normal stress levels and at high infill thicknesses.

One the other hand, the shear resistance of rock bolts and cable bolts has attracted the attention of increasingly more researchers. Stillborg [21] studied the shear performance of fully grouted cable bolts with a single shear test device. It was found that the shear strength of the inclined cable bolt was more than that of the perpendicular ones. Aziz et al. [22] conducted shear tests of bolted concrete blocks reinforced with fully grouted rock bolts with a small scale double shear assembly. Grasselli [6] studied the mechanical responses of untensioned fully grouted rebar and frictional Swellex bolts subjected to double shear tests with unconfined concrete blocks. Jalalifar and Aziz [23, 24] studied the bending behavior of the rebar bolts in concrete blocks with the double shear test method. It was found that the applied axial load on the bolt had a significant effect on the location of the hinge points in different strength concrete, particularly at low strengths. Aziz et al. [25] studied the shear strength properties of plain and spirally profiled cable bolts with a double shear testing apparatus. The results showed that spiral profiles of the outer wires weakened both the tensile and shearing strength.

The studies concentrating on bolts and joints have improved our understanding of the working mode of bolts and the strengthening mechanism of bolts on joints. However, for most engineering projects, quantitative parameters, such as the cohesion and internal friction angle of bolted rocks, are more significant than qualitative conclusions. Some scholars have treated bolted rock masses as a composite material and studied overall strength behavior of bolted rock with or without joints, which is more practical for supporting the scheme design, theory analysis, and numerical simulation of engineering projects. To quantify the influence of bolting parameters on the increase of the shear resistance of joints, Spang and Egger [26] conducted 60 laboratory shear tests on different kinds of rocks with $8 \mathrm{~mm}$ diameter steel bolts. It was concluded that higher reinforcement resistance was obtained in weaker blocks of rock and that the difference in shear strength between rough and very smooth surfaces may be as high as $50 \%$. Hou and Gou [12] implemented physical simulation experiments of bolted concrete blocks and concluded that bolts increased the mechanical parameters of rock, such as the elastic modulus, peak strength, postpeak strength, cohesion, and internal friction angle. Meng et al. [13] studied the

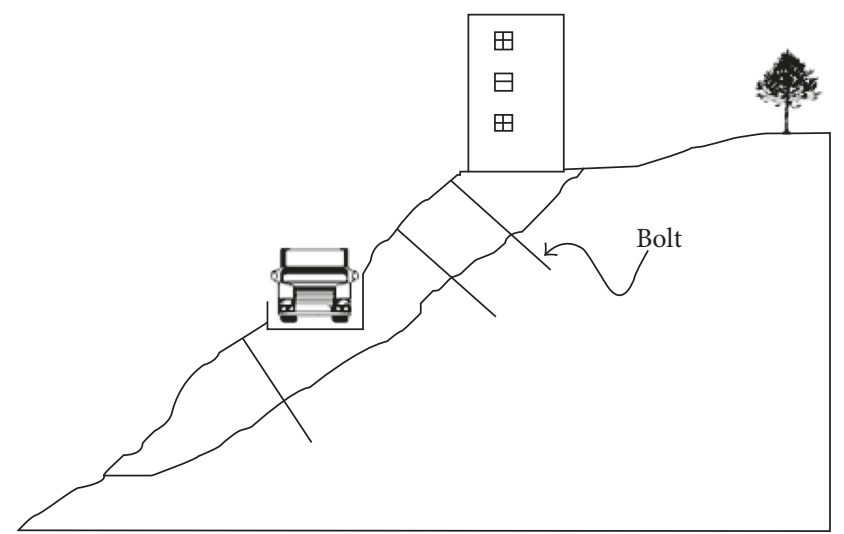

FIGURE 1: Bolts used in slope stability-controlling engineering.

compression bearing behavior of bolted rock, such as material blocks $(500 \mathrm{~mm} \times 500 \mathrm{~mm} \times 500 \mathrm{~mm})$, with a true triaxial compression strength test system. It was concluded that the development of fractures was significantly influenced by bolt tension load and that the compression zone of the bolt plate in a block presented a tube-like shape. Jing et al. [14] conducted large-scale model experiments of bolted rock-like material blocks with prefabricated fractures and found that the peak strength and elastic modulus increased nonlinearly with the increased bolt number for the same joint angle.

Studies showing the strengthening effect of bolts on a rock mass or joint in the current state-of-the-art have been conducted using either a direct shear test or compression test. The load condition in these tests is different from the elastic boundary condition of a rock mass on a slope. The rock mass in the ultimate state of slipping on a slope bears both shear force and normal force, which are split from the vertical gravitational force of a potential slip rock mass. If an additional load, such as a vehicle load or construction load, was applied on the potential slip rock mass, joints inside the rock mass would connect with each other to form a largescale slip plane, which would result in a landslide disaster (Figure 1). As the component of vertical load, the shear force and normal force on the shear plane are proportionally increased during loading, which is different from the loading conditions in ordinary direct shear tests conducted in the laboratory.

In addition, the intact rock between discrete shear planes plays an important role in resisting the complete connection of slipping failure plane, which is critical for preventing slope failure. The reinforcing mechanism of bolted intact rock deserves more attention than only bolted joints.

To determine the quantitative influencing effect of bolts on rock, more than 90 bolted and nonbolted concrete blocks were tested by an oblique shear test apparatus, which applied increasing shear force and normal force proportionally and simultaneously until the test sample reached the failure point.

\section{Experimental Setup}

2.1. Oblique Shear Test Apparatus. The shear test apparatus is composed of two stiff plates, bearing balls, and two dies 


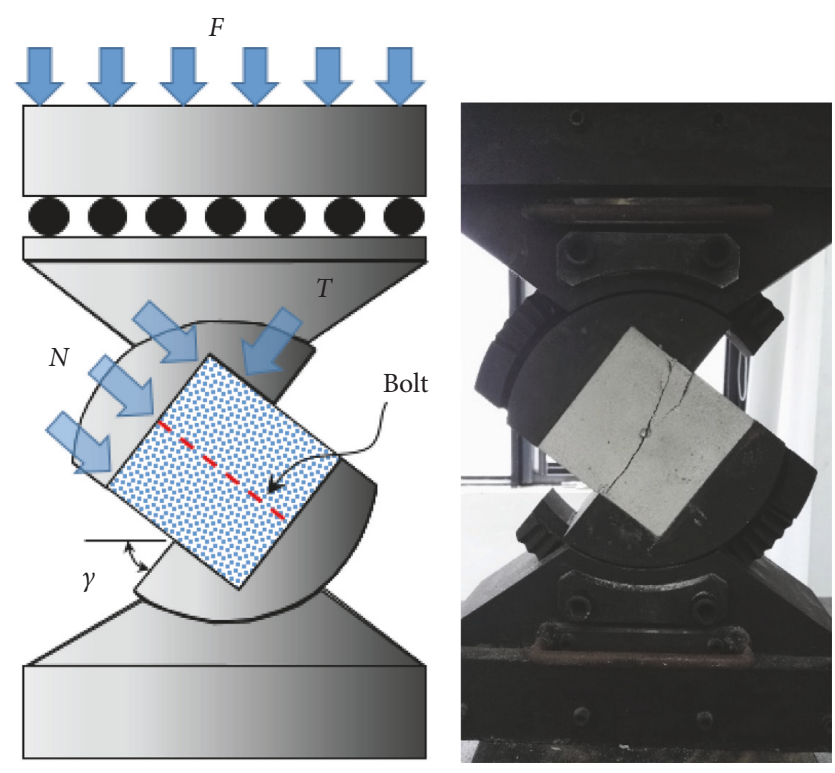

Figure 2: Oblique shear strength test device.

with a gear (Figure 2). The bearing balls set between stiff plates and the dies setup could reduce the friction effect when horizontal displacement develops during the shear test. The two dies setup with gear can afford different oblique angles, which can make different combinations of normal and shear forces from a given vertical load. First, the oblique angle will be set by rotating the gear during the shear test process; then, a cubic specimen with or without bolts is placed between the two dies setups. When $F$ (vertical load) was applied by servocontrol compression machine, the two components of normal and shearing force were applied perpendicularly to and along the shear failure plane, respectively and simultaneously, which is the same as the slope with a potential failure plane and bearing a vertical load from construction and vehicles.

The normal force $(N)$ and shear force $(T)$ acting on the predetermined shear plane are determined by following equations:

$$
\begin{aligned}
& N=F \cos \gamma, \\
& T=F \sin \gamma,
\end{aligned}
$$

where $\gamma$ is the slope angle of the predetermined shear plane, as shown in Figure 2.

The corresponding normal stress and shear stress are defined as

$$
\begin{gathered}
\sigma_{n}=\frac{F \cos \gamma}{a b}, \\
\tau=\frac{F \sin \gamma}{a b},
\end{gathered}
$$

where $\sigma_{n}$ is the normal stress applied on the shear plane, $\tau$ is the shear stress applied on the shear plane, $a$ is the width of the shear plane, and $b$ is the length of the shear plane.

For three different oblique angles $\left(53^{\circ}, 58^{\circ}\right.$, and $\left.63^{\circ}\right)$, three levels of normal force were applied to concrete

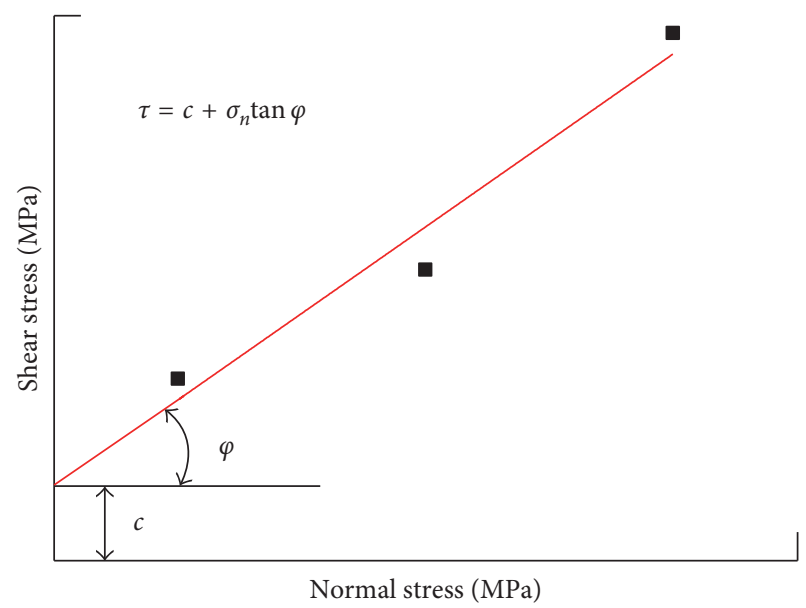

Figure 3: Mohr envelope from oblique shear test.

samples. Three groups of a combination of normal stress and shear stress could be obtained. Then, by fitting these points plotted on the $\sigma_{n} \sim \tau$ diagram, the Mohr envelope could be constructed, and subsequently, the apparent friction angle $(\varphi)$ and apparent cohesion (c) could be determined (Figure 3).

2.2. Sample Preparation. The test concrete blocks in this study were composed of cement, quartz sand, and water. To obtain the maximum mechanical stability and homogeneity of the test samples, pure quartz sand (Figure 4) with three different grain sizes was employed. The size of quartz sand is shown in Table 1. The water: cement: quartz sand ratio was set to $1: 2.18: 2.18$. Four kinds of bolts with diameters of $2 \mathrm{~mm}, 3 \mathrm{~mm}, 4 \mathrm{~mm}$, and $5 \mathrm{~mm}$ were used in this study. To simulate rebar bolts and achieve a better anchoring effect [27], the bolts used in tests were threaded rods with lengths of $9.6 \mathrm{~mm}$. The mechanical parameters of bolts are illustrated in Table 2 .

When preparing the test samples, cement and quartz sand were weighed and completely stirred before mixing with water to ensure the homogeneity of the test sample. Second, concrete mortar was poured in the standard concrete molds $(100 \mathrm{~mm} \times 100 \mathrm{~mm} \times 100 \mathrm{~mm})$ and the bolt was fixed. Third, the standard concrete mold with concrete mortar and bolt was vibrated to remove air bubbles, which may result in the deviation of the mechanical properties of samples. Subsequently, the concrete samples were left for 24 hours to be stripped and then to cure for 15 days at a constant temperature of $35^{\circ}$. Finally, 102 concrete block samples were prepared (Figure 5).

The uniaxial compression tests of concrete blocks without bolts were conducted, and the test samples showed a consistent uniaxial compressive strength of approximately $33 \mathrm{MPa}$.

2.3. Laboratory Testing. More than 90 bolted and nonbolted concrete block samples were tested. A loading strain rate of $0.5 \mathrm{~mm} / \mathrm{min}$ was maintained during all shear tests. The laboratory tests were conducted in two steps. First, no bolt 


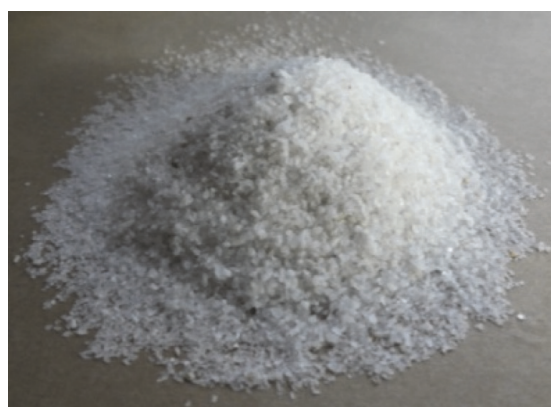

(a)

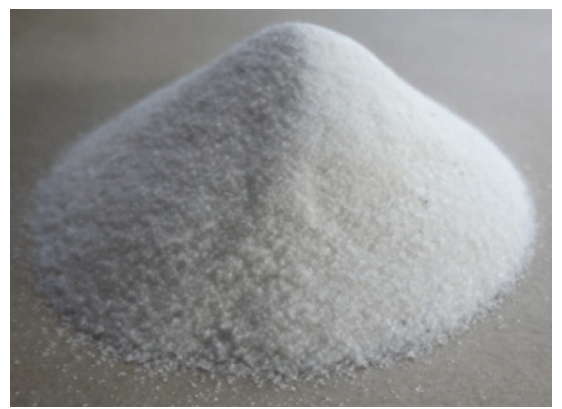

(b)

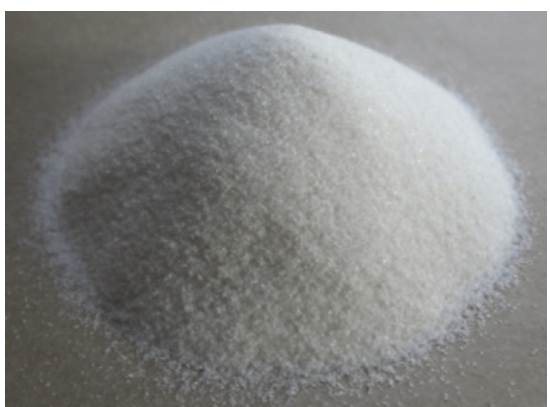

(c)

Figure 4: Pure quartz sand used in test samples. (a) $20 \sim 40 \mu$, (b) $40 \sim 70 \mu$, and (c) $70 \sim 140 \mu$.

TABLE 1: Different sizes of quartz sand used in experiment.

\begin{tabular}{lccc}
\hline \multirow{2}{*}{ Grain size } & \multicolumn{3}{c}{ Quartz sand } \\
& Coarse sand & Medium sand & Fine sand \\
\hline Mesh number & $20-40$ & $40-70$ & $70-140$ \\
Mean grain size $(\mathrm{mm})$ & $>0.5$ & $0.5-0.35$ & $0.35-0.25$ \\
\hline
\end{tabular}

TABLE 2: Mechanical parameters of bolt.

\begin{tabular}{lccc}
\hline $\begin{array}{l}\text { Diameter } \\
(\mathrm{mm})\end{array}$ & $\begin{array}{c}\text { Elastic } \\
\text { modulus } \\
(\mathrm{GPa})\end{array}$ & $\begin{array}{c}\text { Yield } \\
\text { strength } \\
(\mathrm{MPa})\end{array}$ & $\begin{array}{c}\text { Ultimate tensile strength } \\
(\mathrm{MPa})\end{array}$ \\
\hline $2,3,4,5$ & 200 & 300 & 404 \\
\hline
\end{tabular}

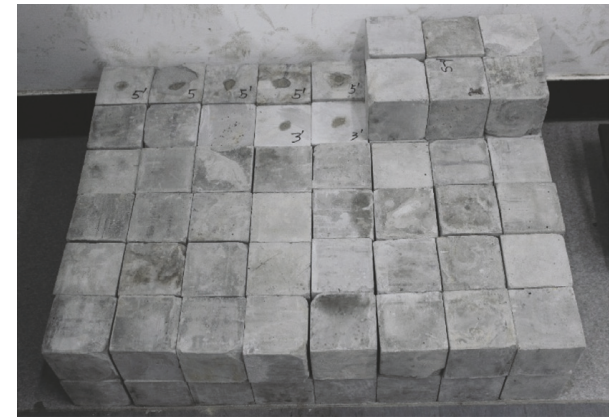

FIGURE 5: Concrete block samples used for shear tests.

samples were tested at different slope angles of the predetermined shear plane, ranging from $53^{\circ}$ to $63^{\circ}$. Next, samples with bolts of different section areas were tested at the same slope angle condition. Thus, the influence of bolt diameter on the overall shear behavior, especially prepeak deformation, peak shear strength, residual shear strength, and dilation of concrete blocks, could be quantified. A typical shear test sample failure is shown in Figure 6.

\section{Results and Discussion}

3.1. Influence of Bolt on Shear Behavior at the Prepeak Stage. Figure 7 illustrates the shear strength profile of the reinforced concrete blocks with different bolts under different shear plane angles. The shear strength curves for bolts with different diameters overlap with each other at the same shear plane angle, which indicates that the bolt diameter has no

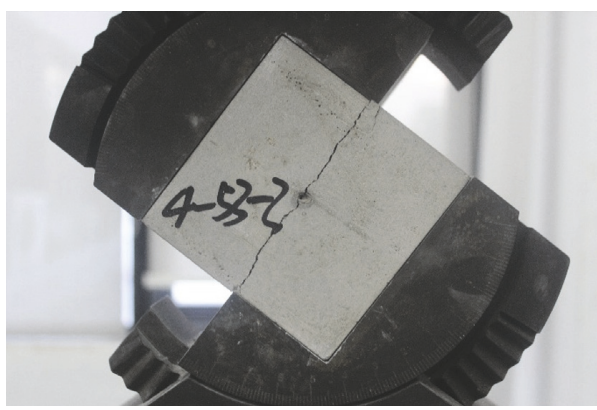

(a)

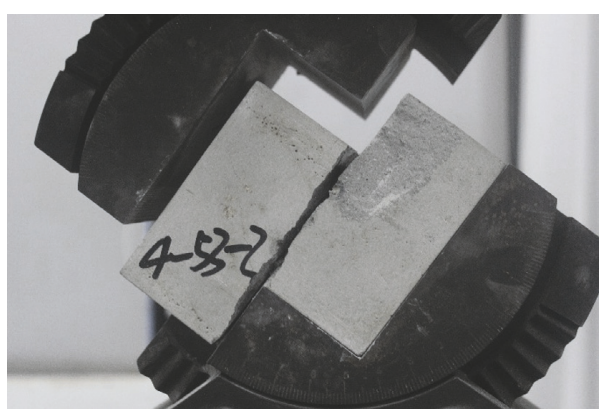

(b)

Figure 6: Shear failure of the test sample. (a) Beginning of shear slip; (b) complete failure of the test sample.

evident influence on prepeak shear behavior of reinforced concrete blocks with untensioned grouted bolts.

The average shear stiffness values of the bolted concrete blocks are $148.12 \mathrm{kN} / \mathrm{mm}, 150.42 \mathrm{kN} / \mathrm{mm}$, and $170.95 \mathrm{kN} / \mathrm{mm}$ for shear plane angles of $63^{\circ}, 58^{\circ}$, and $53^{\circ}$, respectively. The shear stiffness increases with the increasing shear plane angle, especially when the shear plane angle exceeds $58^{\circ}$. The average peak shear strengths are $184.40 \mathrm{kN}, 216.17 \mathrm{kN}$, and $263.47 \mathrm{kN}$ at shear plane angles of $63^{\circ}, 58^{\circ}$, and $53^{\circ}$, respectively. In conclusion, the normal force has a significant effect on the prepeak shear behavior (including shear stiffness and peak shear strength) of bolted and nonbolted concrete blocks.

3.2. Influence of Bolt on Shear Behavior at the Postpeak Strength Stage. As shown in Figure 7, it is evident that there is a sudden drop in the shear behavior curve after peak shear strength, especially with small-diameter bolts and low 


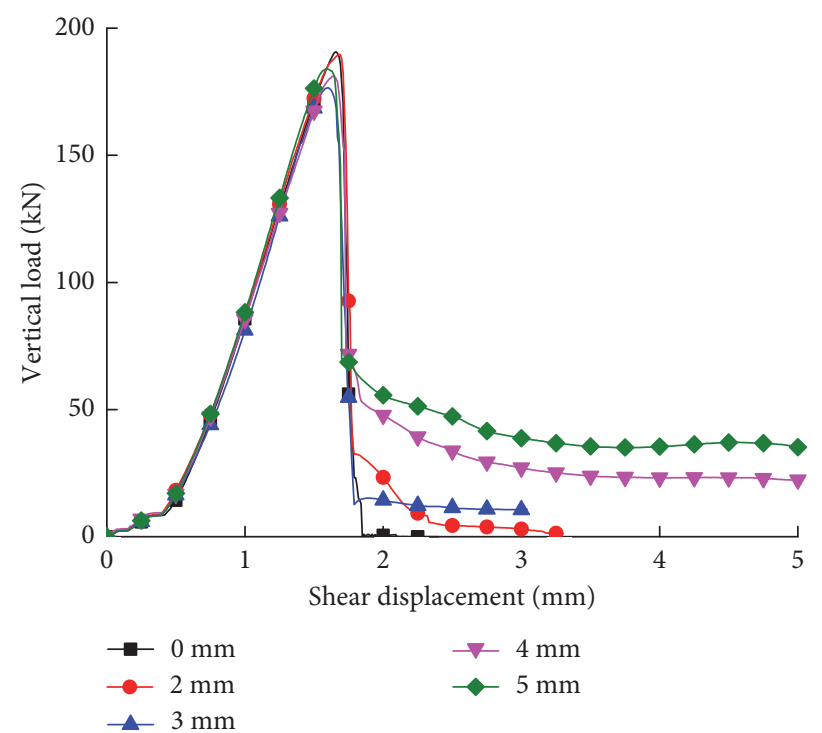

(a)

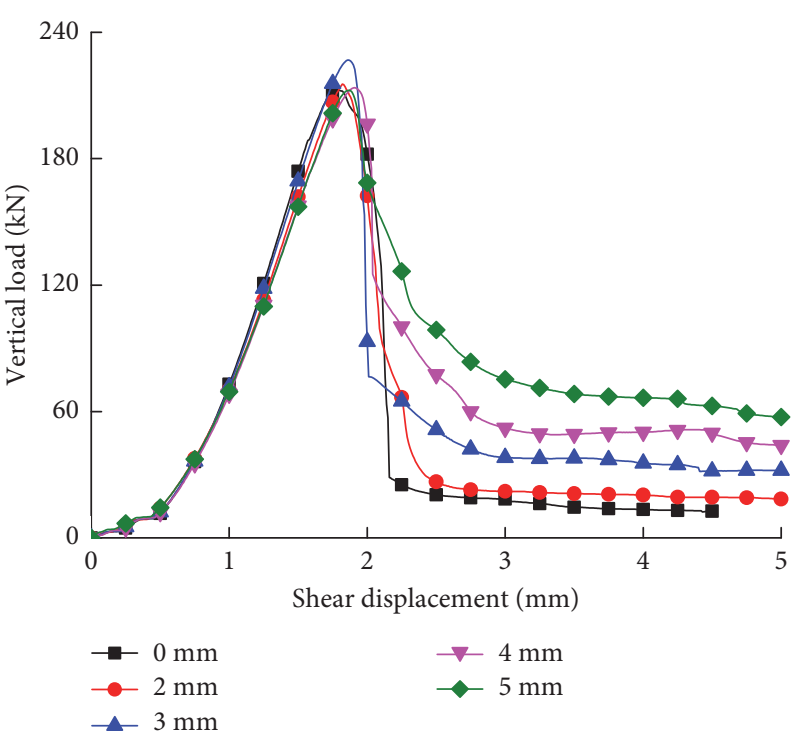

(b)

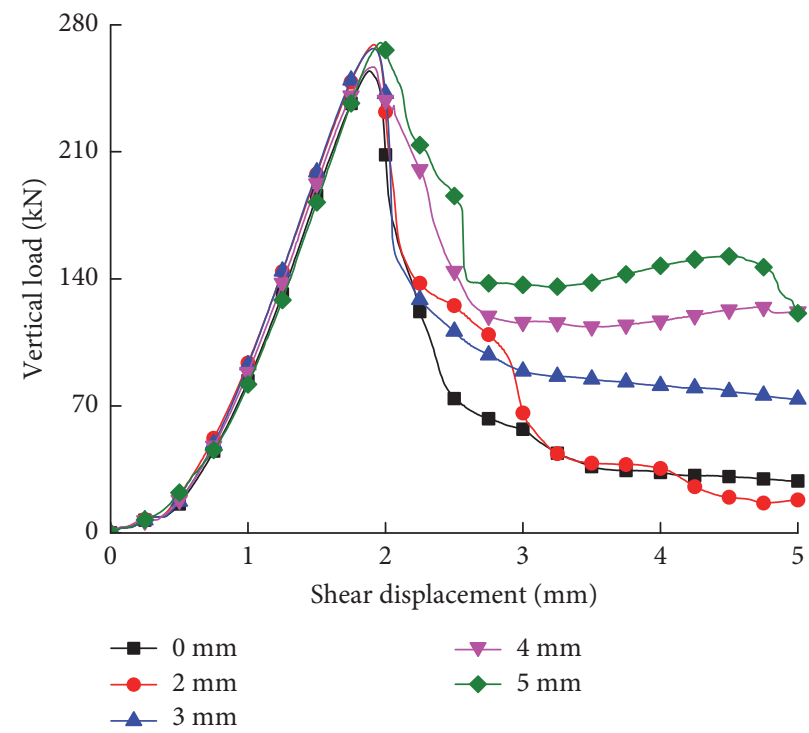

(c)

FigURE 7: Shear strength profile of bolted concrete blocks with different slope angles of the shear plane ranging from $63^{\circ}$ to $53^{\circ}$. (a) $\gamma=63^{\circ}$; (b) $\gamma=58^{\circ}$; (c) $\gamma=53^{\circ}$.

confining pressure (i.e., when the shear plane angle is greater than $58^{\circ}$ ). For higher normal force or larger-diameter bolts, there is a gentle falling slope of the shear strength curve. The sudden collapse of rock in slope engineering could cause serious casualties; the resistance provided by bolts at the postpeak stage discussed above is satisfactory. To quantify such contribution of the bolt to the shear resistance of the test samples, the percentage drop of shear strength after the peak point is presented in Figure 8.

As illustrated in Figure 8, nonbolted concrete blocks have the largest drop of shear strength at all levels of normal stress. The residual shear strength approximates zero, especially when shear plane angle is $63^{\circ}$. The drop in shear strength increases with an increase in the shear plane angle, which indicates that normal force has a significant effect on the postpeak shear behavior of the tested samples. It is also observed that the percentage drop in shear strength decreases with an increase in the bolt diameter. As expected, the contribution of bolts to the postpeak shear behavior of the bolted samples is more significant as the bolt diameter increases, verifying the favorable effect of bolts on jointed rocks [12].

At the high slope angle of the shear plane, the differences in the percentage drops in the shear strength between samples with different diameters of bolts are 15\% 20\%, which is more evident than that at the low slope angle of the shear plane. This indicates that normal force has reduced the influence of bolts on the postpeak shear behavior of reinforced samples. The discontinuities developed in slopes are always nonplanar, which will result in dilation during shear slip processes. Bolts could passively provide additional 


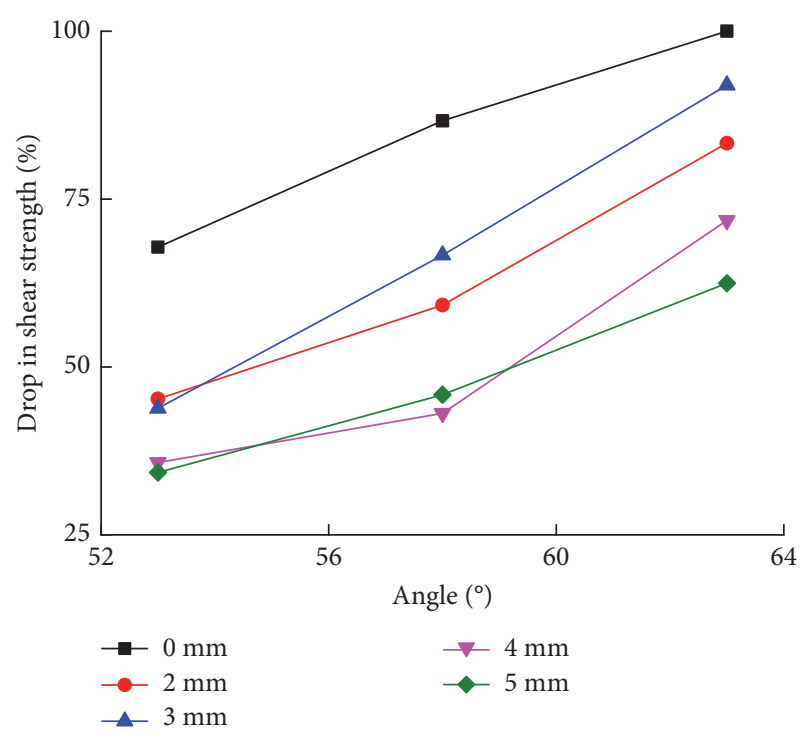

FIGURE 8: Variation of percentage drop of shear strength of concrete block after peak point with different bolt diameters.

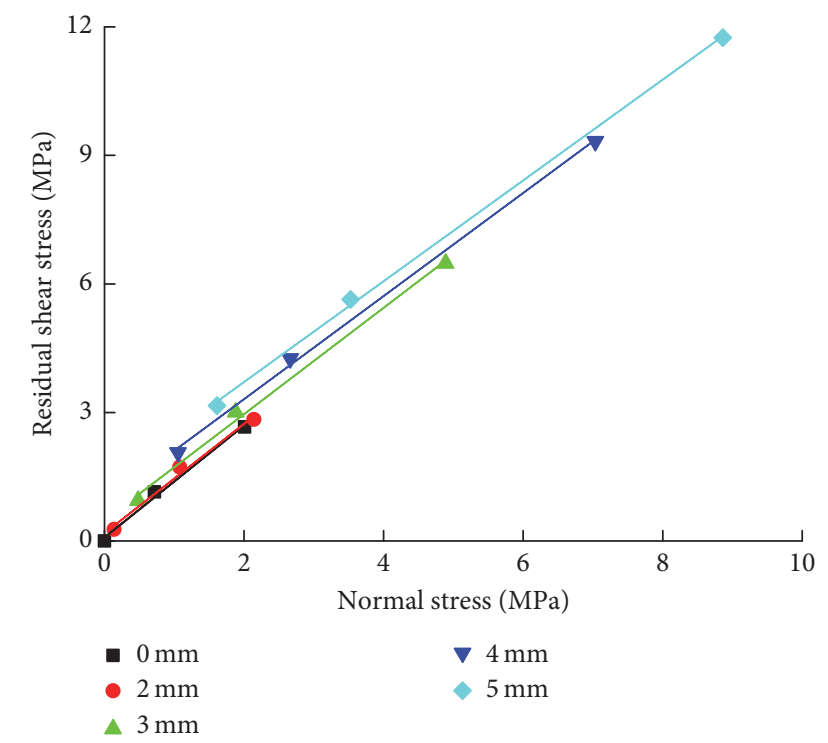

FIGURE 9: Residual shear strength envelopes of concrete blocks with and without bolt.

normal force due to the dilation effect, which is important for the stability control of slopes and more critical for those with abrupt discontinuities.

\subsection{Influence of Bolt on Residual Shear Strength Stage.} Figure 9 shows the residual shear strength envelopes plotted for test samples with bolts of different diameters. It is clear that the residual shear strength envelopes of the test samples are basically linear and do not overlap with each other due to the differences in the bolt diameter. When a bolt diameter is small (no more than $2 \mathrm{~mm}$ ), the residual shear strength envelope of the bolted concrete block overlaps with that of the nonbolted sample. The differences in the ratio of residual shear stress to normal stress between bolted concrete blocks increase with

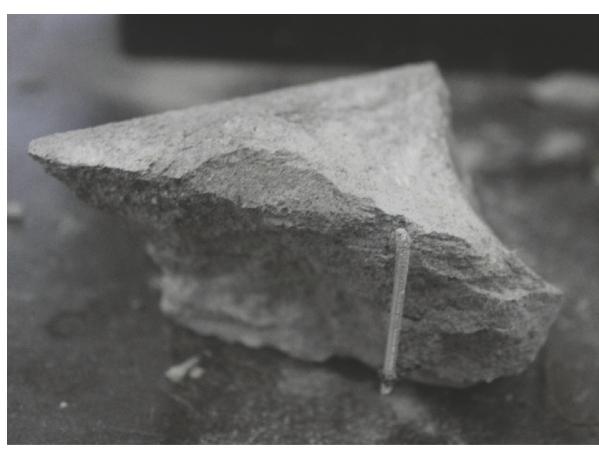

(a)

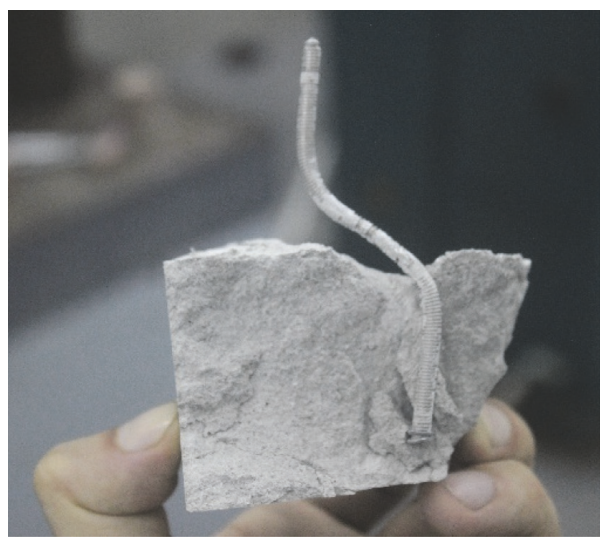

(b)

FIgURE 10: Failure of bolts. (a) Diameter of bolt $=2 \mathrm{~mm}$; (b) diameter of bolt $=4 \mathrm{~mm}$.

any increase in the bolts' diameter. In conclusion, the bolt would provide significant shear resistance of rock at the residual shear slip stage only when the diameter of the bolt exceeds a critical value.

Figure 10 shows the failure of bolts after the shear test. The bolt with the small diameter, limited tension strength, and stiffness would break in the vicinity of the shear plane, while the bolt with the large diameter just deflected and formed a hinge shape. When the diameter of the bolt is $2 \mathrm{~mm}$, the bolt is broken up under the combined effect of the shear load and tension load and could not continue to provide shear resistance to the failed concrete block. The concrete block with the failed bolt exhibited the same shear behavior as the nonbolted samples. Although the bolt with a larger diameter inflected in the vicinity of the shear failure plane of concrete block at the postpeak shear strength stage, additional normal force and direct shear resistance could still be persistently provided, which maintained residual shear strength of slipping blocks.

To obtain a more quantitative conclusion of the reinforcing mechanism of the bolt, a dimensionless notation of $r_{\mathrm{b}}$ was defined as the ratio of the cross-sectional area of the bolt to the area of the shear failure plane, which is expressed by following equation:

$$
r_{b}=\frac{A_{\mathrm{b}}}{A_{\mathrm{r}}} \times 100 \%,
$$

where $A_{\mathrm{b}}=$ cross-sectional area of the bolt and $A_{\mathrm{r}}=$ area of the shear failure plane. 


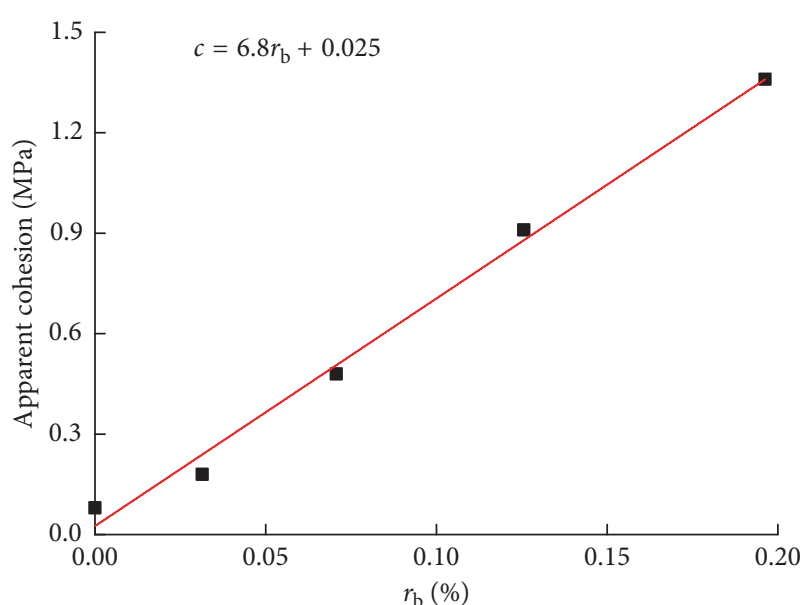

(a)

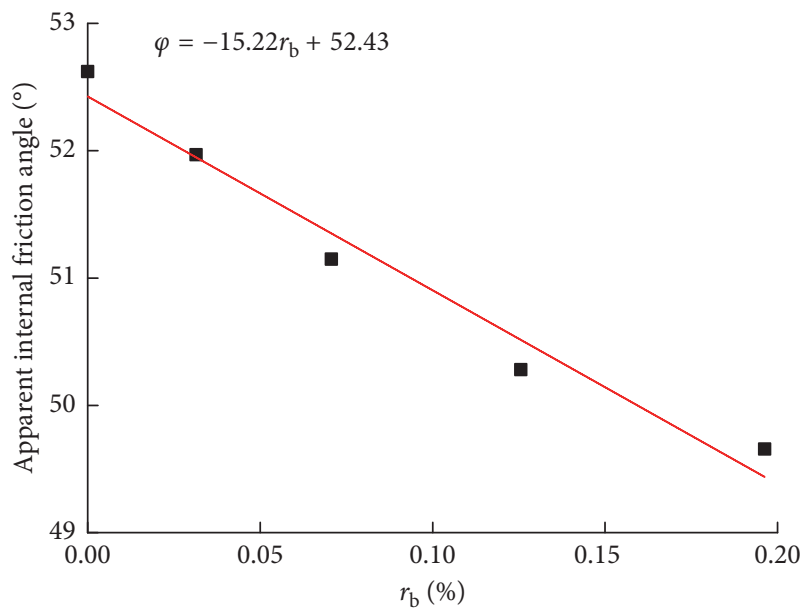

(b)

Figure 11: Two shear resistance components of concrete blocks with different $r_{\mathrm{b}}$ in residual shear slip stage. (a) Apparent cohesion; (b) apparent internal friction angle.

The relationship between the basic mechanical parameters (apparent cohesion and apparent internal friction angle) of bolted concrete blocks in the residual shear strength stage and $r_{\mathrm{b}}$ is shown in Figure 11.

As shown from Figure 11, although the residual shear strength of the bolted concrete blocks increases with any increase in the diameter of the bolt, two components of the residual shear resistance show the opposite trend with $r_{\mathrm{b}}$. An empirical model of apparent cohesion, expressed as the ratio of residual shear stress to normal stress, could be obtained by linear regression, which is expressed as

$$
c=6.8 r_{\mathrm{b}}+0.025 \text {. }
$$

The corresponding empirical model of the apparent internal friction angle could be expressed as

$$
\varphi=-15.22 r_{\mathrm{b}}+52.43
$$

The reinforcing effect of rock bolts in current studies of stability analysis of slope and underground engineering is always simplified due to the complexity of the interaction mechanisms between bolts and rock. The failure of the bolt is determined by the tension strength of the rod, the shear strength of the grout, or the cohesion between the rod, grout, and host rock in numerical models and theoretical analysis, which result in the difficulty of calculations and the deviation from realistic conditions. Equations (4) and (5) could provide a direct reference for determining the shear resistance of a bolted rock mass, which would make the determination of reinforcing the effect of the bolt in a numerical simulation or theoretical analysis more simple and quantitative.

\section{Conclusions}

(1) The bolt has no evident influence on the prepeak shear behavior (shear stiffness and peak shear strength) of intact concrete blocks.

(2) The percentage drop in the peak shear strength of a concrete block after failure significantly decreases with an increase in bolt diameter, verifying the satisfying performance of the bolt on the residual shear strength of the bolted concrete block.

(3) As a component of the vertical load perpendicular to the shear plane, normal force increases with the decrease in the slope angle of the shear plane and has a significant effect on the shear behavior of the concrete block, especially the residual shear strength.

(4) At a high slope angle of the shear plane, the differences in the percentage drop in shear strength between samples with different diameters of bolts are 15\% $20 \%$, which is more evident than that at the low slope angle of shear plane, indicating the effectiveness of the bolt in the stability control of slopes with steep fractures.

(5) Bolts would provide significant shear resistance of rock at the residual shear slip stage only when the diameter of the bolt exceeds a critical value. Although the bolt with a larger diameter inflected in the vicinity of the shear failure plane of concrete block at the postpeak shear strength stage, additional normal force and direct shear resistance could still be persistently provided, which maintained residual shear strength of slipping blocks.

(6) The empirical equations of apparent cohesion and the apparent internal angle of the bolted concrete block were obtained by linear regression: $c=6.8 r_{\mathrm{b}}+0.025$; $\varphi=-15.22 r_{\mathrm{b}}+52.43$.

\section{Conflicts of Interest}

The authors declare that they have no conflicts of interest.

\section{Acknowledgments}

The authors acknowledge the projects supported by the $\mathrm{Na}$ tional Natural Science Foundation for Young Scientists of China (Grant no. 51504247), National Natural Science Foundation Key Projects of China (Grant no. 51734009), 
Natural Science Foundation of Jiangsu Province for Distinguished Young Scholars (Grant no. BK20150005), National Natural Science Foundation of China (No. 41572263), and National Innovation Project of University Students (Grant no. 201610290010).

\section{References}

[1] S. Bjurström, "Shear strength of hard rock joints reinforced by grouted untensioned bolts," in Proceedings of the $3 \mathrm{rd}$ International Conference of the ISRM Congress, pp. 1194-1199, Denver, CO, USA, September 1974.

[2] C. J. Haas, "Analysis of rock bolting to prevent shear movement in fractured ground," Minerals Engineering, vol. 33, pp. 698-704, 1981.

[3] A. M. Ferrero, "The shear strength of reinforced rock joints," International Journal of Rock Mechanics and Mining Sciences \& Geomechanics Abstracts, vol. 32, no. 6, pp. 595-605, 1995.

[4] G. Grasselli, M. Kharchafi, and P. Egger, "Experimental and numerical comparison between fully grouted and frictional bolts. Swiss Federal Institute of Technology, Lausanne, Switzerland," in Proceedings of the International Congress on Rock Mechanics, pp. 903-907, Paris, France, 1999.

[5] B. Indraratna, N. I. Aziz, and A. Dey, "Behaviour of joints containing clay infill under constant normal stiffness, with and without bolting," Geotechnical Engineering, vol. 149, no. 4, pp. 259-267, 2001.

[6] G. Grasselli, "3D behaviour of bolted rock joints: experimental and numerical study," International Journal of Rock Mechanics and Mining Sciences, vol. 42, no. 1, pp. 13-24, 2005.

[7] B. Ludvig, "Shear tests on rockbolts," in Proceedings of the International Symposium on Rock Bolting, pp. 113-123, Abisko, Sweden, August-September 1983.

[8] C. C. Li, "A new energy-absorbing bolt for rock support in high stress rock masses," International Journal of Rock Mechanics and Mining Sciences, vol. 47, no. 3, pp. 396-404, 2010.

[9] Y. Chen and C. C. Li, "Performance of fully encapsulated rebar bolts and D-Bolts under combined pull-and-shear loading," Tunnelling and Underground Space Technology, vol. 45, pp. 99-106, 2015.

[10] X. W. Li, N. Aziz, A. Mirzaghorbanali, and J. Nemcik, "Comparison of the shear test results of a cable bolt on three laboratory test apparatuses," Tunnelling and Underground Space Technology, vol. 61, pp. 81-89, 2017.

[11] A. Mirzaghorbanali, H. Rasekh, N. Aziz, G. Y. Yang, S. Khaleghparast, and J. Nemcik, "Shear strength properties of cable bolts using a new double shear instrument, experimental study, and numerical," Tunnelling and Underground Space Technology, vol. 70, pp. 240-253, 2017.

[12] C. J. Hou and P. F. Gou, "Mechanism study on strength enhancement for the rocks surrounding roadway supported by bolt," Chinese Journal of Rock Mechanics and Engineering, vol. 19, no. 3, pp. 342-345, 2000.

[13] B. Meng, H. W. Jing, K. F. Chen, and H. J. Su, "Failure mechanism and stability control of a large section of very soft roadway surrounding rock shear slip," International Journal of Mining Science and Technology, vol. 23, no. 1, pp. 127-134, 2013.

[14] H. W. Jing, S. Q. Yang, M. L. Zhang, G. A. Xu, and K. F. Chen, "An experimental study on anchorage strength and deformation behavior of large-scale jointed rock mass," Tunnelling and Underground Space Technology, vol. 43, pp. 184-197, 2014.
[15] J. J. Azuar, Stabilisation des Massifs Rocheux Fissurés Par Barres d'acier Scellées, Rap. de Rech, LPC No. 73, Lab. Central des Ponts et Chaussees, Paris, France, 1977.

[16] S. Hibino and M. Motojima, "Effects of rock bolting in jointy rocks," in Proceedings of the International Symposium on Weak Rock, pp. 1057-1062, Tokyo, Japan, September 1981.

[17] P. M. Dight, "Improvement to the stability of rock walls in open pit mine," Ph.D. thesis, Monash University, Melbourne, VIC, Australia, 1982.

[18] P. Egger and H. Fernandez, "Nouvelle presse triaxiale-etude de modèles discontinus boulonnés," in Proceedings of the International Conference on ISRM, pp. 171-175, Melbourne, VIC, Australia, 1983.

[19] P. Egger and L. Zabuski, "Behaviour of rough bolted joints in direct shear tests," in Proceedings of the 7th ISRM Congress, pp. 1285-1288, Aachen, Germany, September 1991.

[20] F. Pellet and P. Egger, "Analytical model for the mechanical behaviour of bolted rock joints subjected to shearing," Rock Mechanics and Rock Engineering, vol. 29, no. 2, pp. 73-97, 1996.

[21] B. Stillborg, "Experimental investigation of steel cables for rock reinforcement in hard rock," Ph.D. thesis, Lulea University, Lulea, Sweden, 1984.

[22] N. Aziz, D. Pratt, and R. Williams, "Double shear testing of bolts," in Coal Operators' Conference, pp. 154-161, University of Wollongong, Wollongong, NSW, Australia, 2003.

[23] H. Jalalifar and N. Aziz, "Analytical behaviour of bolt joint intersection under lateral loading conditions," Rock Mechanics and Rock Engineering, vol. 43, no. 1, pp. 89-94, 2010.

[24] H. Jalalifar and N. Aziz, "Experimental and 3D numerical simulation of reinforced shear joints," Rock Mechanics and Rock Engineering, vol. 43, no. 1, pp. 95-103, 2010.

[25] N. Aziz, R. Hawker, A. Mirzaghorbanali, J. Nemcik, X. Li, and H. Rasekh, "Strength characteristics of Secura hollow groutable cable bolts," in Proceedings of the Coal Operator Conference, Wollongong, Australia, 2015.

[26] K. Spang and P. Egger, "Action of fully grouted bolts in jointed rock and factors of influence," Rock Mechanics and Rock Engineering, vol. 23, no. 3, pp. 201-229, 1990.

[27] M. Ghadimi, K. Shariar, and H. Jalalifar, "A new analytical solution for calculation the displacement and shear stress of fully grouted rock bolts and numerical verifications," International Journal of Mining Science and Technology, vol. 26, no. 6, pp. 1073-1079, 2016. 


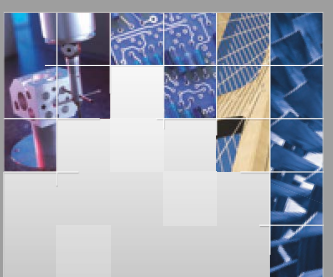

\section{Enfincering}
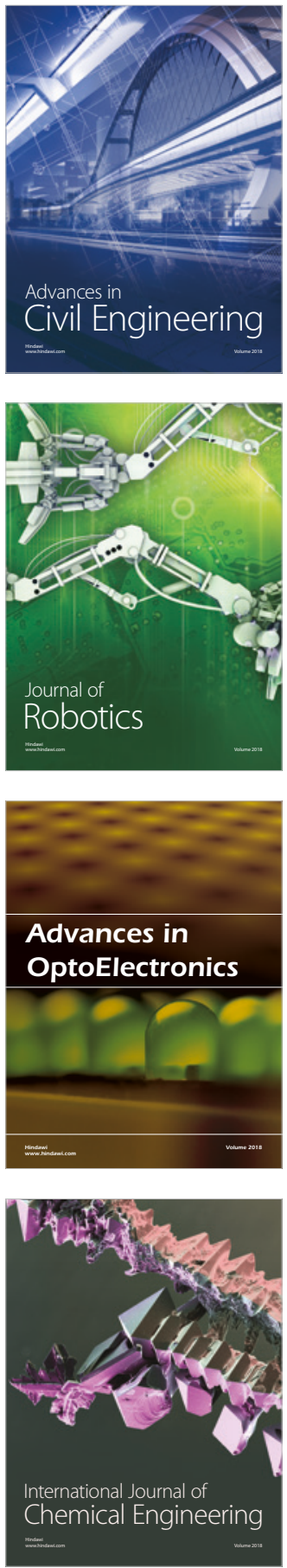

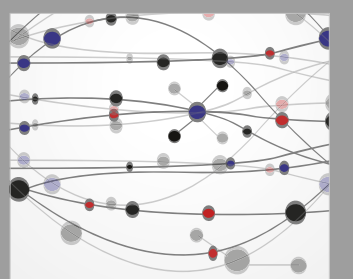

\section{Rotating \\ Machinery}

The Scientific World Journal

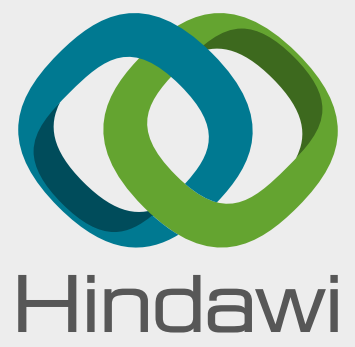

Submit your manuscripts at

www.hindawi.com
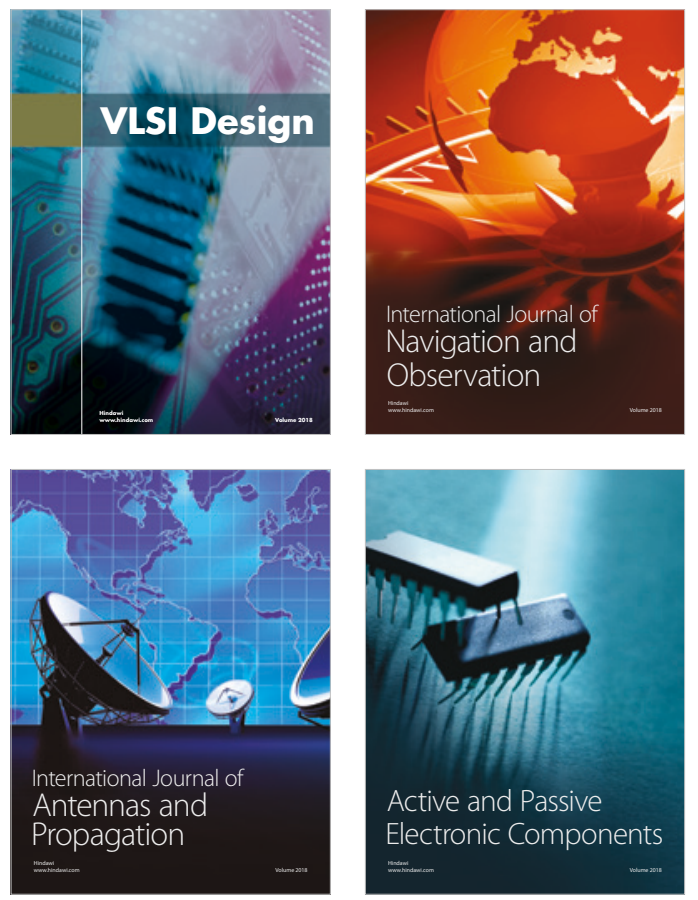
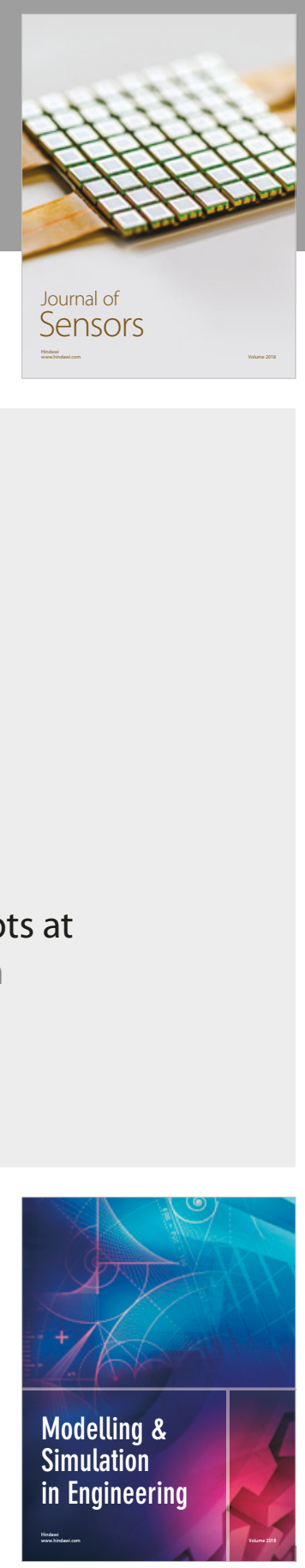

\section{Advances \\ Multimedia}
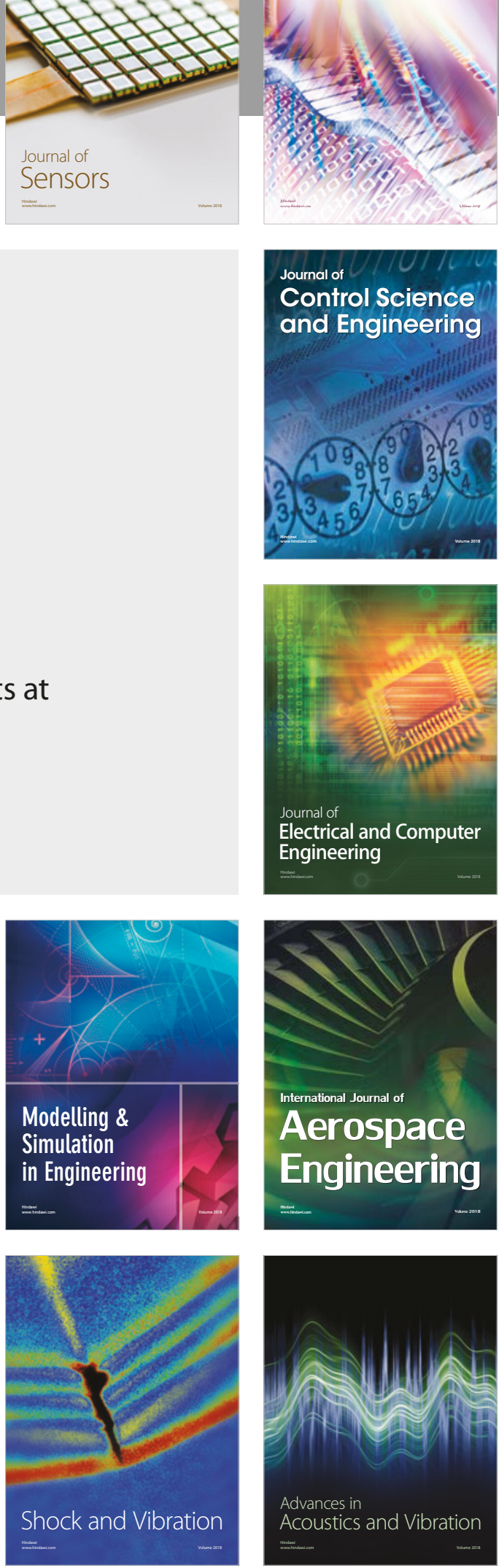